\title{
Lipophilic cage ligands: synthesis, spectroscopic properties and applications
}

\author{
Silvio Quici*a, Pier Lucio Anelli ${ }^{a}$, Henriette Molinari ${ }^{a}$, \\ and Tiziana Beringhelli \\ a Centro C.N.R. and Dipartimento di Chimica organica e \\ Industriale dell'Università, I-20133 Milano, Italy. \\ Dipartimento di Chimica Inorganica e Metallorganica \\ dell'Università, I-20133 Milano, Italy.
}

\begin{abstract}
A $\underline{b}$ 느므믄 - Macropolycyclic lipophilic ligands, capable of solubilizing inorganic salts in non polar organic solvents, can be efficiently used as anion activators or ion carriers through membranes. In this context we recently reported the synthesis of new lipophilic ligands $\underline{6}$ assisted by the template effect of sodium cation. Due to the high rigidity imposed by the short bridging chains ligands $\underline{6}$ form very stable sodium complexes in non-polar media, even when very hydrophilic and poorly polarizable anions are involved. This makes it easy to perform base-promoted reactions: e.g. carbanion formation from very weak carbon acids under phase-transfer conditions. X-Ray analysis of a sodium perchlorate complex showed that the cation is embedded in a non-symmetric cubic cage. The assignment of all resonances of ${ }^{1} \mathrm{H}$ and ${ }^{13} \mathrm{C}$ NMR spectra was achieved by using two-dimensional techniques. At room temperature the free ligand is in a fast conformational equilibrium as shown by a ${ }^{13} \mathrm{C}$ NMR investigation at variable temperature. However, in the sodium perchlorate complex only the portion of the molecule on the side of the alkyl group is affected by lowering the temperature, while the remaining part showed no conformational change down to $-60^{\circ} \mathrm{C}$. Ligands $\underline{6}$ were obtained by continuous extraction with $\underline{n}$-hexane from an aqueous solution of their methoxide or fluoride sodium complexes. This allowed the preparation and the study of complexes with different metal cations, as $\mathrm{K}^{+}, \mathrm{Ag}^{+}, \mathrm{Cu}^{+}$etc..
\end{abstract}

\section{INTRODUCTION}

The first macrobicyclic synthetic ligands (cryptands) 1 were introduced by Lehn in 1969 (ref. 1); they are capable of binding metal cations into the intramolecular cavity forming very stable and selective inclusion complexes (cryptates) (ref. 2). Subsequently more sophisticated ligands (e.g. $\underline{2}$ and $\underline{3}$ ) showing an higher topological discrimination were synthesized (ref. 3 ).

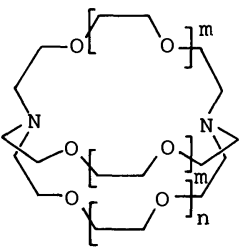

$\underline{1}$

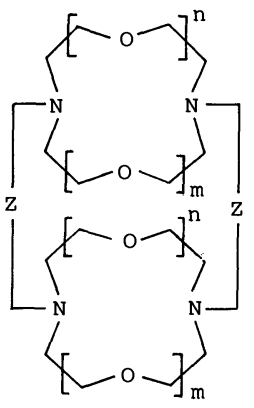

$\underline{2}$

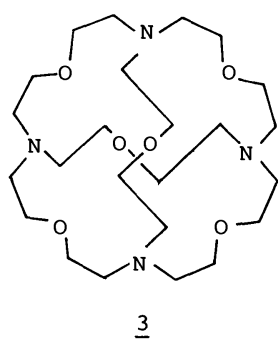

$\underline{3}$ 
The carbon atom/heteroatom ratio of these macropolycyclic polydentate ligands is generally very low $(\leq 2.4)$ in accordance with their prominent hydrophilic character. These ligands can, in principle, be made lipophilic by introducing one or more hydrophobic functions (ref. 4-7). Functionalization influences the rigidity and size of the intramolecular cavity and leads to a variation of stability constants and complexation selectivities, the effect being more pronounced when phenyl or cyclohexyl groups are a part of one or more bridging chains (ref. 8-10). The introduction of a long alkyl chain affords lipophilic systems with complexation features similar to those of the corresponding non alkylated derivatives. Lipophilic multidentate ligands, capable of dissolving inorganic salts in non-protic non-polar organic solvents, are of particular interest mostly for the study of the properties of ions in hydrophobic media, the transport through natural or artificial lipidic membranes and the anion activation (ref. 2,11 ).

The main object of our research is the synthesis of multidentate ligands bearing lipophilic alkyl chains and/or suitable functionalities in order to allow their immobilization into insoluble polymeric matrices. The lipophilic [2.2.2- $\left.{ }_{14}\right]$ cryptand $\underline{4}$ was obtained by using the high dilution technique in cyclization steps (ref. 12), however this technique is not of pratical interest in the synthesis of [1.1.1] cryptand due to the very low yields (ref. 13). The lipophilic proton cryptate $\left[\mathrm{H}^{+} \mathrm{C}\left(1.1 .1-\mathrm{C}_{14}\right)\right] \mathrm{x}^{-}$的 and the corresponding non alkylated cryptate $5 \underline{b}$ were prepared 4 in good yields following an original synthetic method in which an intramolecular hydrogen bond acts as a templating agent driving the macrobicyclic ring closure (ref. 14). Moreover the template effect of an appropriate metal cation represents a valid alternative to the classical method of preparation of other cryptands (ref. 15,16$)$.

The anion plays an important role on the stability of the metal cation complexes. In non-polar organic media complexes with very hydrophilic and/or poorly polarizable anionic counterparts, e.g. $\mathrm{OH}^{-}, \mathrm{F}^{-}$, etc., decompose to a more or less great extent, thus making the activation of these kinds of anions very difficult. In this context the synthesis of new ligands capable of forming complexes with very high stability constants represents an interesting field of research.

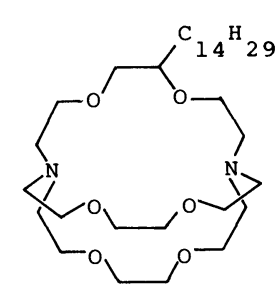

$\underline{4}$

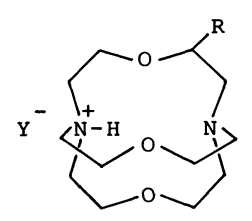

5a $\quad R=\underline{n}^{-C_{14}}{ }_{29}$

b $\quad R=H$

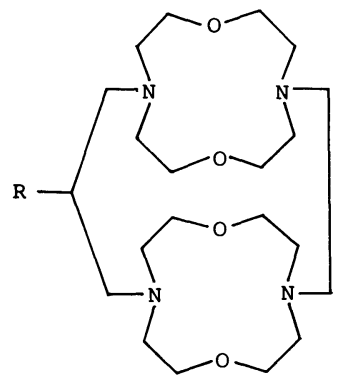

ㅁa $\mathrm{R}=\underline{\mathrm{n}}-\mathrm{C}_{16^{\mathrm{H}}}{ }_{33}$

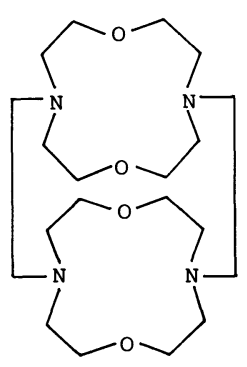

?

$\underline{\mathrm{b}} \mathrm{R}=\mathrm{CH}_{2} \mathrm{Ph}$

\section{LIPOPHILIC CAGE LIGANDS}

\section{Synthesis}

The macropolycyclic ligands $\underline{6} \underline{a}$ and $\underline{6} \underline{b}$, whose lipophilicity is ensured by the presence of an alkyl residue, form very stable sodium complexes even in low polarity solvents.

They represent a new class of lipophilic cage ligands whose peculiar feature is the presence of very short bridging chains, (ref. 17). Indeed the two macrocyclic subunits cooperate in the complexation of only one metal cation giving rise to mononuclear inclusion complexes. The formation of binuclear inclusion complexes, which is unlikely with $\underline{6}$, occurs easily when the bridges consist of at least five carbon atoms (ref. 18). The synthesis of the

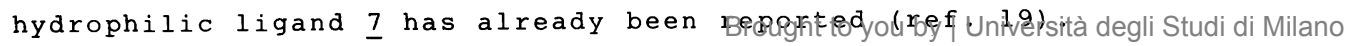




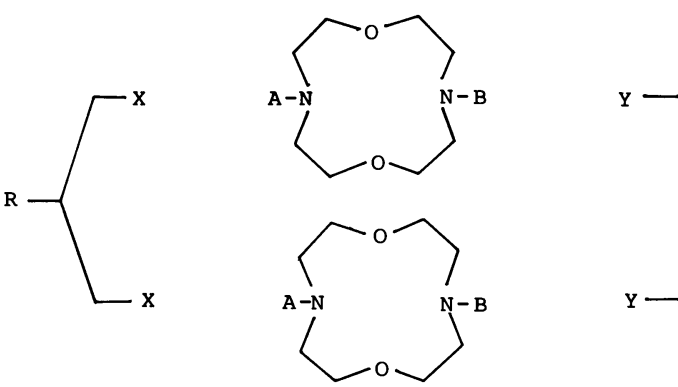

Fig.l Disconnection of ligands $\underline{6}$ into fragments.

Ligand $\underline{6}$ can be imagined disconnected into fragments as shown in figure 1. For the synthesis of $\underline{6}$ it was necessary to prepare the diazacoronand in which the two nitrogen atoms bear two protecting groups which can be selectively removed. The synthetic path followed for monoprotected diazacoronand is reported in scheme 1. Debenzylation can be realized by catalytic hydrogenation or, alternatively, through the formation of the urethane, the subsequent alkaline hydrolysis and decarboxylation (ref. 17).

The fragments are finally assembled as reported in scheme 2. The last step of the synthesis which leads to the macrotricyclic structure occurs in 60-70\% yields, and is assisted by the template effect of the sodium cation. Other cations, e.g. lithium or silver, are ineffective; in fact, when they were used instead of sodium, only unresolvable polymeric mixtures were obtained. This synthetic approach directly affords the sodium p-toluenesulphonate complexes which can be converted into the more easily purified perchloraces $\underline{8} a$ and $\underline{8} \underline{b}$. The perchlorates $\underline{8}$ allow also the preparation of many other sodium complexes via anionic exchange (equation l). Due to the insolubility of potassium perchlorate the equilibrium is shifted to the right.

$$
\begin{aligned}
& {\left[\mathrm{Na}^{+} \mathrm{C} \underline{6}\right] \mathrm{ClO}_{4}^{-}+\mathrm{KX} \longrightarrow\left[\mathrm{Na}^{+} \mathrm{C} \underline{6}\right] \mathrm{x}^{-}+\mathrm{KClO}_{4}} \\
& \mathrm{X}=\mathrm{I}, \mathrm{Cl}, \mathrm{Br}, \mathrm{F}, \mathrm{OH}, \mathrm{MeO}, \text { etc.. }
\end{aligned}
$$

The preparation of complexes following equation 1 is a very versatile method and it is also the only one possible when the free ligand is not available. The template synthesis of multidencase ligands often leads to stable complexes (as in the case of 6 ), the greater their stability the more difficult the decomplexation.

Scheme 1
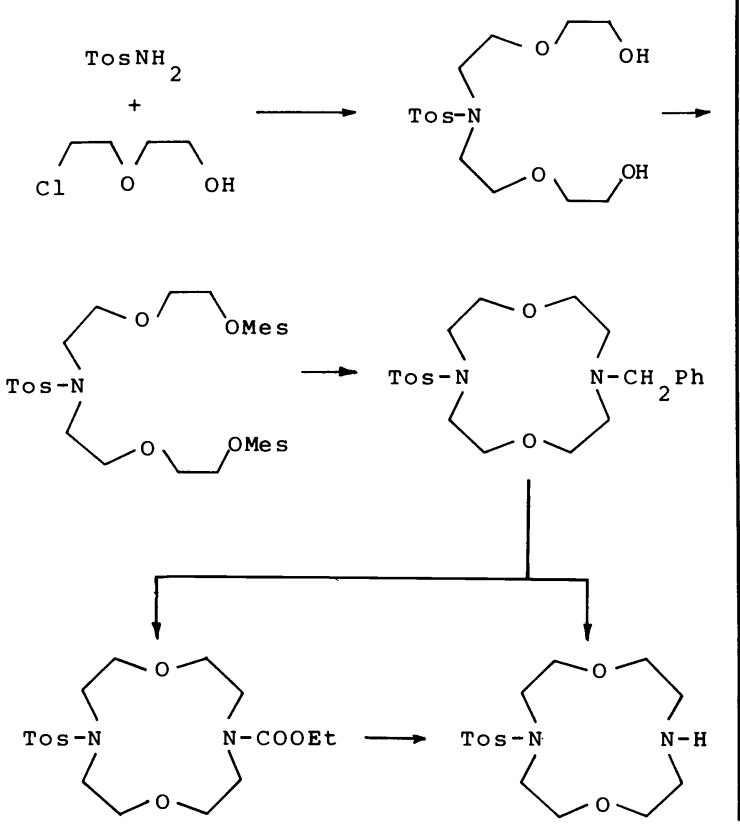

Scheme 2

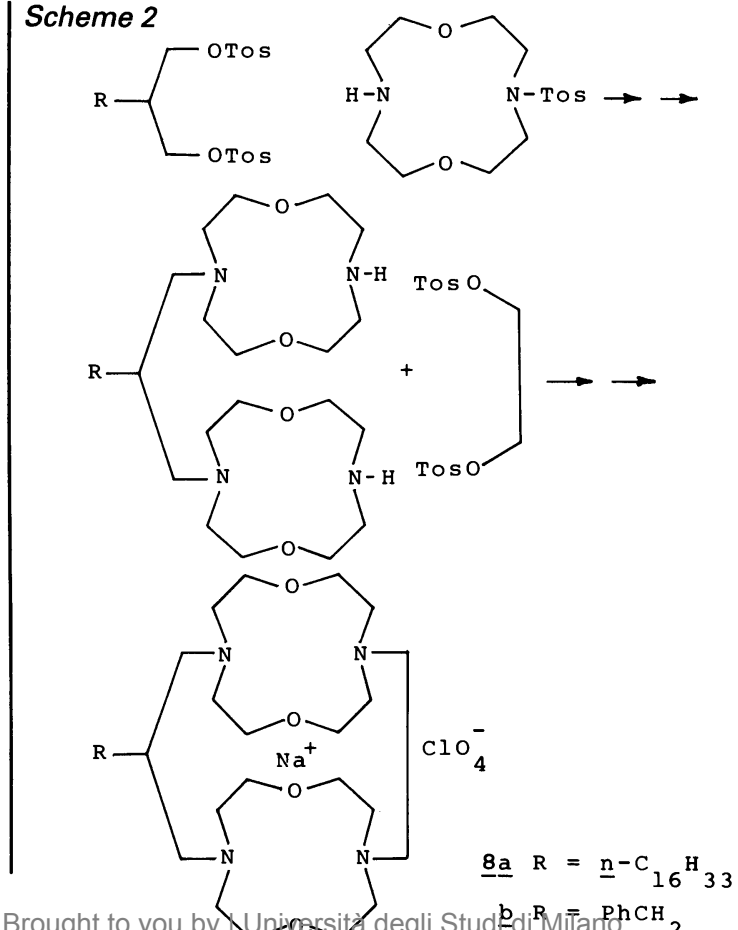

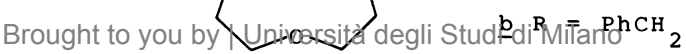




\section{Decomplexation}

Ligands 6 were obtained from a solution of the corresponding sodium methoxide or sodium fluoride complexes in methanol-water by continuous extraction with $\underline{n}$-hexane for several days. In the case of very stable lipophilic complexes the factors influencing the shift of equilibrium 2 to the right are essentially the lipophilicity of the ligand and the nature of the anionic counterpart. Ligand $\underline{6} \underline{a}$, which is more lipophilic than $\underline{6} \underline{b}$, is extracted more

$$
\left[\mathrm{Na}^{+} \mathrm{C} \underline{6}\right] \mathrm{x}^{-} \rightleftharpoons \underline{6}+\mathrm{Na}^{+}+\mathrm{x}^{-}
$$

efficiently. Hydrophilic anions (e.g. $\mathrm{OH}^{-}, \mathrm{F}^{-}$) speed-up the decomplexation, whereas lipophilic anions (e.g. $\mathrm{ClO}_{4}{ }^{-}, \mathrm{I}^{-}$) make this process too slow to be of practical interest. The rate of decomplexation can be increased by heating the aqueous phase.

The achievement of the free ligand by this method allowed the preparation of complexes with different metal cations like $\mathrm{K}^{+}$, $\mathrm{Ag}^{+}$and $\mathrm{Cu}^{+}$.

\section{Spectroscopic properties}

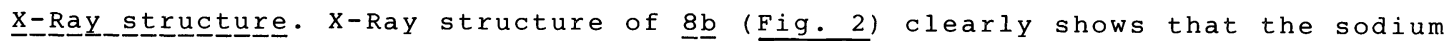
cation is located at the center of the ligand cavity and is 6.7 A from the baricenter of the anion (ref. 20). The donor atoms are located around the metal cation in a distorted culic conformation, the four oxygen and the four nitrogen atoms laying respectively on two perpendicular planes. The distances $\mathrm{Na}{ }^{+}$... o are comparable with those found for the sodium fluoborate complex of $\underline{7}$ (ref. 2l) whereas the $\mathrm{Na}^{+}$....N distances are almost $0.1 \AA$ longer due to the different lengths of the two bridges and to the high rigidity of the complex.

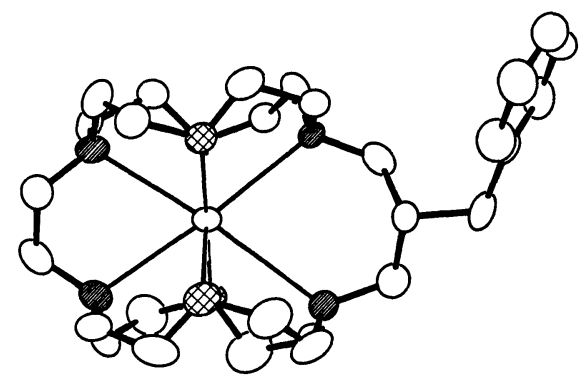

Fig. 2. $x$-Ray structure of the sodium perchlorate complex $\underline{8} \underline{b}$.

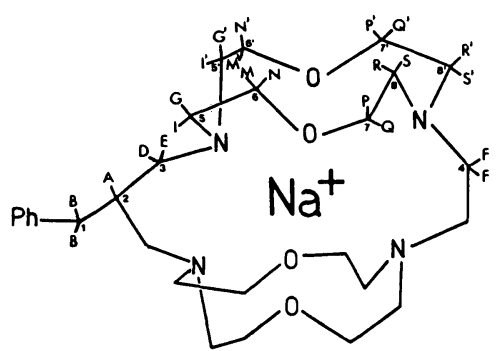

[CIO. $]^{-}$

Fig. 3. Carbons and hydrogens identification in the structure of $\underline{8}$ b.

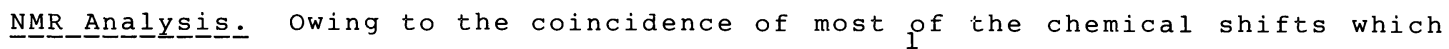
results in strongly overlapped multiplets, the ${ }_{H}$ NMR spectrum of $\underline{8} b$ is very complicated and the assignment of resonances was impossible using monodimensional conventional tecniques, even at $500 \mathrm{MHz}$. The complete characterization of $\underline{8} \underline{b}$ has been achieved by using homonuclear and heteronuclear shift correlated two dimensional experiments (ref. 22). The strategy followed for the assignment of resonances of $\underline{8} \underline{b}$ ( $\underline{\text { Fig. 3) }}$, which has been used for all the other systems, is based on the recognition of the signals of the hydrogens belonging to the same $\mathrm{OCH}_{2} \mathrm{CH}_{2} \mathrm{~N}$ fragment and of those of the bridges through $\mathrm{H}_{-} \mathrm{H}$ homonuclear shift correlated (COSY) experiments (Fig. 4). The starting point was in every case the correlation of the methine hydrogen of the three carbon bridge with the hydrogens of Cl methylene (Fig. 4) which, for 8 b. are the only ones coupled with the aromatic protons. The ${ }^{13}$ C NMR spectrum is also complicated and resonances have been assigned by using heteronuclear shift correlated experiments (Fig. 5). The ${ }^{3}$ C NMR spectrum of $\underline{8}$ b shows 12 resonances in the aliphatic region confirming the presence of an apparent $\mathrm{C}_{\mathrm{S}}$ symmetry which has been shown by the $\mathrm{x}$-ray structure.

The conformational analysis of ligands $\underline{6}$ and their complexes $\underline{8}$ was performed by ${ }^{C}$ NMR spectroscopy at variable temperatures ( their complexity, ${ }_{H}$ NMR spectra cannot be used for conformational studies. 


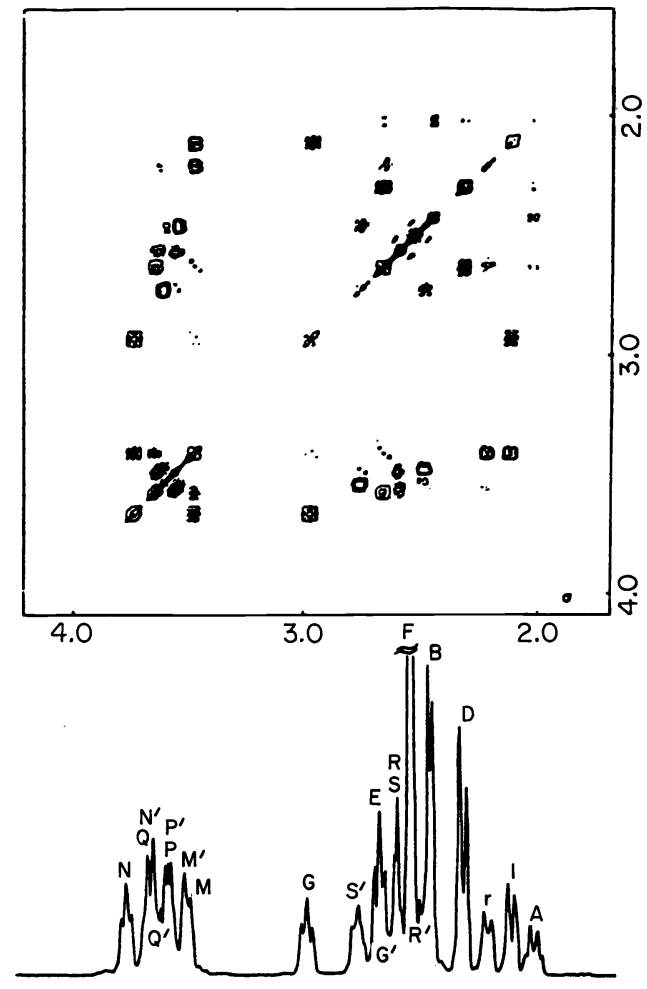

Fig. 4. ${ }^{1} \mathrm{H}$ 2D chemical shift correlated COSY spectrum of $\underline{8} \underline{b}$ presented as a contour plot. Aliphatic region ( $500 \mathrm{MHz}_{2} \mathrm{CDCl}_{3}$ ).

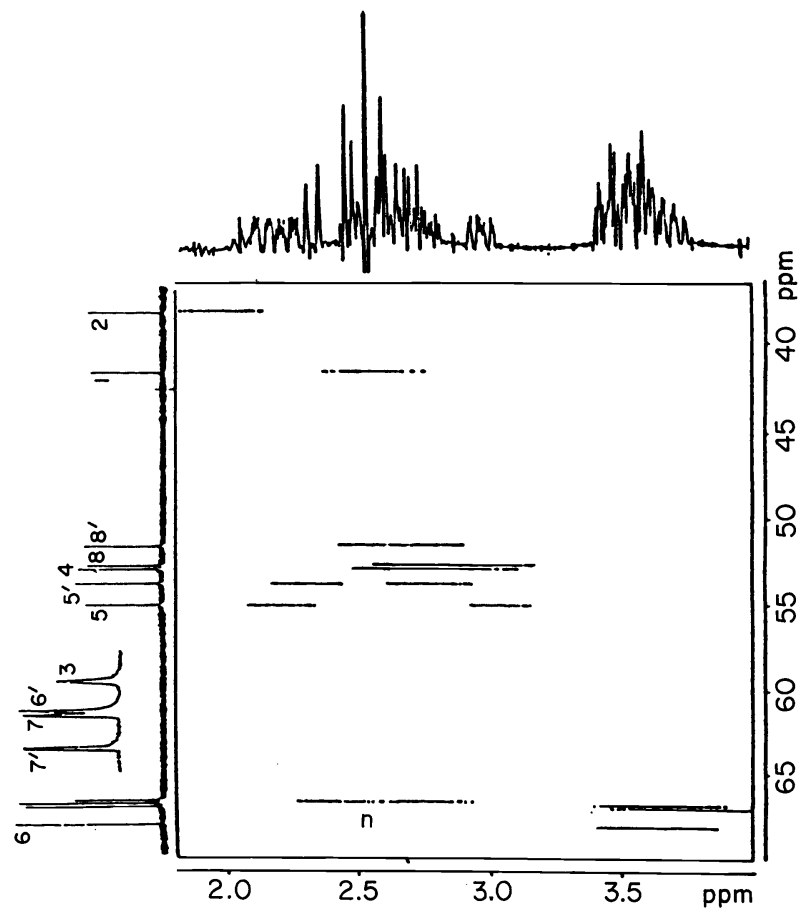

Fig. 5. ${ }^{13} \mathrm{C}^{1}{ }_{\mathrm{H}}$ Heteronuclear shift correlated 2D NMR spectrum of $\underline{6} \underline{b}$ presented as a contour plot. Aliphatic region $\left(75.43 \mathrm{MHz}, \mathrm{CDCl}_{3}\right)$.

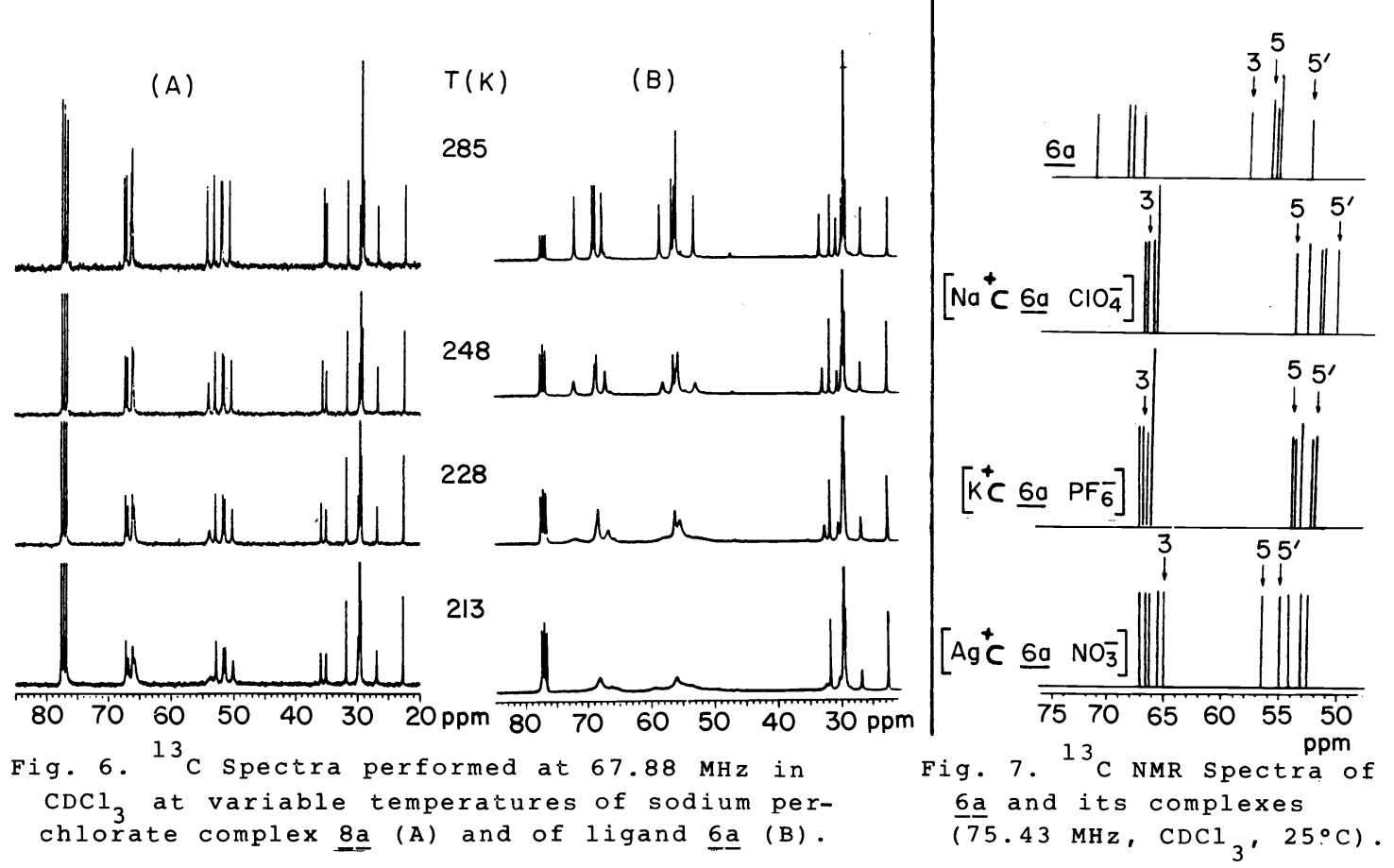


At room temperature the ligand $\underline{6}$ a is in rapid conformational equilibrium; by lowering the temperature all the resonances of the macrotricyclic structure change and coalesce at $-60^{\circ} \mathrm{C}$. Quite different is the case of complex $\underline{8} a$ where only the resonances of carbons C2, C3, C5, C5', C6 and C6' are affected by decreasing the temperature, the remaining signals are still sharp at $-60^{\circ} \mathrm{C}$. These results suggest that only the portion of the molecule containing the alkyl residue is involved in conformational changes (ref. 23).

The chemical shift of the ${ }^{13} \mathrm{C}$ resonances of ligand $\underline{6}$ a and its complexes with $\mathrm{NaClO}_{4}, \mathrm{KPF}_{6}$ and $\mathrm{AgNO}_{3}$ are reported in figure 7; as a consequence of complexation all the carbon resonances are shifted upfield. The only exception is for the two C3 carbons which move downfield (ref. 23). Analogous behaviour has been found for the sodium chloride complex of ligand $\underline{7}$ (ref. 19). As shown in figure 7, the different chemical shifts of C3, C5, and C5' carbons of the silver nitrate and the sodiun perchlorate complexes of $\underline{6} a$, can be explained in terms of conformational changes, probably because of a stronger interaction of silver with the nitrogen atoms. ${ }^{13} \mathrm{C}$ NMR showed that complexation of copper (I) by ligand $\underline{6} \underline{b}$ readily occurs in the presence of $\left[\mathrm{Cu}\left(\mathrm{CH}_{3} \mathrm{CN}\right)_{4}\right]^{+} \mathrm{PF}_{6}^{-}$in acetonitrile (ref. 23 ).

TABLE 1. Second-order rate constants for nucleophilic substitutions on n-octyl methanesulphonate by anio.ss $X$ associated with $\left[\mathrm{Na}^{+} \subset \underline{6} a\right],\left[\mathrm{Na}^{+} \subset \underline{6} \underline{b}\right]$ and $\left[\mathrm{K}^{+} \mathrm{C}\left(2.2 .2-\mathrm{C}_{14}\right)\right]$ in anhydrous chlorobenzene at $60^{\circ} \mathrm{C}$.

\begin{tabular}{|c|c|c|c|}
\hline \multirow{2}{*}{$x$} & \multicolumn{3}{|c|}{$\mathrm{kx} 10^{2}, \mathrm{M}^{-1} \mathrm{~s}^{-1}$} \\
\hline & {$\left[\mathrm{Na}^{+} \subset \quad \underline{6} \underline{a}\right]$} & {$\left[\mathrm{Na}^{+} \subset \underline{6} \underline{b}\right]$} & {$\left[K^{+} \subset\left(2.2 .2, C_{14}\right)\right]^{a}$} \\
\hline I & 0.90 & 0.86 & 0.87 \\
\hline $\mathrm{Br}$ & - & 2.8 & 3.7 \\
\hline $\mathrm{C} 1$ & 2.3 & 3.2 & 5.1 \\
\hline
\end{tabular}

a From ref. 25.

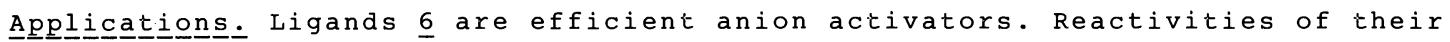
sodium halide complexes in nucleophilic aliphatic substitution reactions on n-octyl methanesulphonate are reported in table l together with those obtained with the $\left[\mathrm{K}^{+} \mathrm{C}\left(2.2 .2-\mathrm{C}_{14}\right)\right] \mathrm{x}^{-}$cryptates in the same conditions. However the main interest for 6 rests on the possibility of obtaining highly stable complexes with alkali cations in non polar organic media, even when hydrophilic and/or poorly polarizable anions (e.g. $\mathrm{OH}^{-}, \mathrm{MeO}^{-}$, etc..) are involved. The solubility of these complexes is ensured by the lipophilicity of the ligand which, as previously stressed, is higher for $\underline{6}$ a. This has been used as an activator in base promoted reactions both under solid/liquid and liquid/liquid phase transfer conditions. By using catalytic amounts of $\underline{6}$ a and in the presence of aqueous sodium hydroxide it has been possible to remove a proton from very weak carbon acids; for example, in the presence of $\underline{6} a$, a mixture of diphenylmethane ( $\mathrm{pKa}=33$ ) and $50 \%$ aqueous NaOH stirred for lh at $70^{\circ} \mathrm{C}$ in an oxygen atmosphere quantitatively afforded benzophenone. In the same conditions, and in the presence of chlorobenzene as solvent, 3-benzylpyridine ( $\mathrm{pKa}=30$ ) was quantitatively transformed into the corresponding ketone after $6 \mathrm{~h}$. It is worth noting that triphenylmethane (pKa $=31.5$ ), in these same conditions, affords the triphenylcarbinol very slowly. The sodium salt of the latter, owing to its lipophilicity, remains preferentially in the organic phase associated with the cation complex thus slowing down the catalytic process. The rate of these reactions increases by raising the concentration of sodium hydroxide; this is in agreement with results recently reported by Landini et al. (ref. 25, 26).

Potassium tentertbutoxide is slightly soluble both in aliphatic and aromatic hydrocarbons forming aggregates. In non polar solvents, clustering is at the maximum and the ability to react with a proton is at the minimum, the reverse occurs in DMSO where highly reactive monomeric species are present (ref. 27). 
TABLE 2. Elimination reactions promoted by potassium teert-butoxide in solid-liquid phase transfer conditions in the presence of 6 a as catalyst.

\begin{tabular}{|c|c|c|c|c|c|c|}
\hline Substrate & $\begin{array}{l}\text { Cat./Sub. } \\
\text { mol. ratio }\end{array}$ & Solvent & $\begin{array}{l}\text { Temperature } \\
{ }^{\circ} \mathrm{C}\end{array}$ & $\begin{array}{l}\text { Time } \\
\text { min. }\end{array}$ & Product & $\begin{array}{c}\text { Yield } \\
\text { s }\end{array}$ \\
\hline $\mathrm{C}_{15} \mathrm{H}_{31} \mathrm{CH}_{2} \mathrm{Cl}$ & 1 & toluene & 25 & 120 & $\mathrm{C}_{14}{ }_{29}^{\mathrm{H}} \mathrm{CH}=\mathrm{CH}_{2}$ & 80 \\
\hline $\mathrm{C}_{15}^{15} \mathrm{H}_{31}^{31} \mathrm{CH}_{2}^{2} \mathrm{Cl}$ & 0.2 & toluene & 85 & 120 & $\mathrm{C}_{14}^{14} \mathrm{H}_{29}^{29} \mathrm{CH}=\mathrm{CH}_{2}^{2}$ & 84 \\
\hline $\mathrm{C}_{15}^{15} \mathrm{H}_{31} \mathrm{CH}_{2} \mathrm{Br}$ & 1 & toluene & 25 & 5 & $\mathrm{C}_{14}^{14} \mathrm{H}_{29}^{29} \mathrm{CH}=\mathrm{CH}_{2}^{2}$ & 83 \\
\hline $\mathrm{C}_{14}^{15}{ }_{29}^{\mathrm{H}}{ }_{29} \mathrm{CH}_{\mathrm{Br}} \mathrm{CH}_{\mathrm{Br}}{ }^{2}$ & 0.01 & $\underline{n}$-hexane & 50 & 360 & $\mathrm{C}_{14}^{14}{ }_{29}{ }_{29} \mathrm{C} \equiv \mathrm{CH}$ & 85 \\
\hline $\mathrm{C}_{10} \mathrm{O}^{\mathrm{H}} 21 \underset{\mathrm{Br}}{\mathrm{CH}-\mathrm{CH}} \mathrm{C}^{\mathrm{CH}}{ }^{1}$ & 0.01 & $\underline{n}$-hexane & 60 & 120 & $\mathrm{C}_{10} \mathrm{H}_{21}^{\mathrm{C}} \equiv \mathrm{CH}$ & 81 \\
\hline
\end{tabular}

The reactivity of tert-butoxide anion is strongly increased in non polar solvents e.g. toluene, n-hexane, etc.. by adding $\underline{6} a$ which transforms the aggregates into extremely reactive separated ion pairs. Some significative examples of terrt-butoxide activation promoted by $\underline{6} a$ in $\beta$-elimination reactions are reported in table 2 .

Alkenes and alkynes are obtained from the corresponding alkyl halides and víc-dihalides respectively in high yields and very mild conditions. The activation due to $6 a$ allows these reactions, which normally require high temperatures and long reaction times (ref. 28), to be performed at room temperature.

\section{Other lipophilic cage ligands}

The structure of ligand $\underline{6}$ can be modified by changing the bridging chains or the macrocyclic subunits (ref. 29). Examples are compounds $\underline{9}$ and 10 which were prepared following the same synthetic strategy used for $\underline{6}$. Compound $\underline{9}$ was obtained in $70 \%$ yield by reacting the same precursor of $\underline{6}$ b with 1,3-propanediol bis(methanesulphonate) in the presence of potassium carbonate. The high yield of $\underline{9}$ is clearly due to the templating effect of the potassium cation. This latter, after ring closure, is no longer coordinated, probably due to the higher flexibility of the ligand, so that $\underline{9}$ is directly isolated from the reaction mixture.
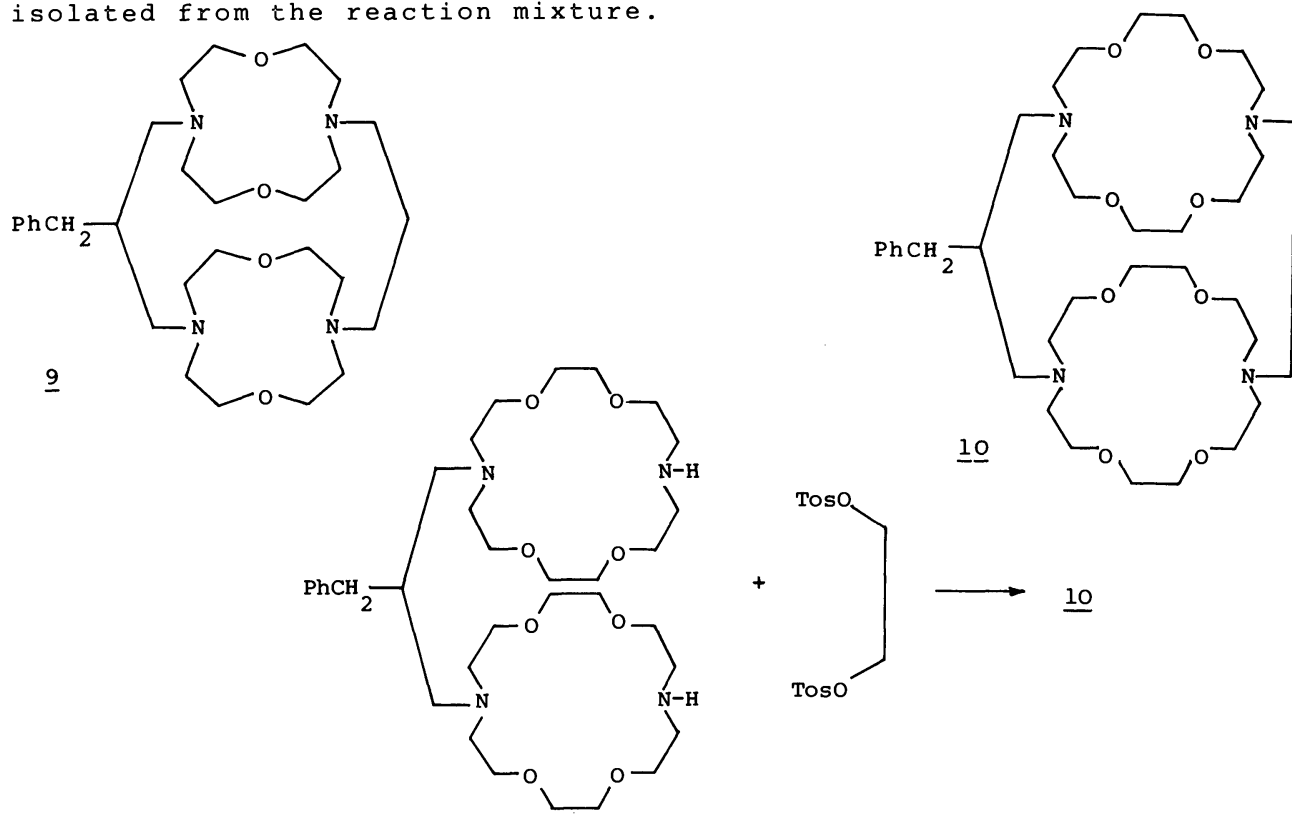

The last step in the synthesis of 10 is shown in equation 3 ; in this case also, potassium carbonate has been used as a base. Ligand lo has been isolated in only $10 \%$ yield, thus excluding any templating effect. Due to the large size of its molecular cavity, lo does not complex any alkali metal

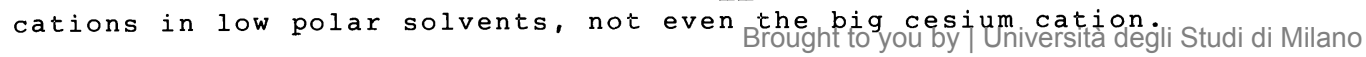


The difficult synthesis of macropolycyclic multidentate ligands makes their use justifiable only if they can be recovered and recycled (ref. 25). The immobilization into insoluble polymeric matrices represents the method of choice since the properties of the soluble ligand are mainly retained by the immobilized species; moreover, it has been shown that the catalytic efficiency of polymer supported macrocycles under phase transfer conditions is only slightly lower compared with that of the corresponding soluble systems (ref. 30). Ligand ll 1 , bearing an hydroxyl function, has therefore been synthesized and it is expected to afford the immobilized cage ligand 12 when bonded to chloromethylated polystyrene using the Williamson reaction. Investigations aimed at a wider application of these ligands, both as soluble and immobilized species, are in progress.
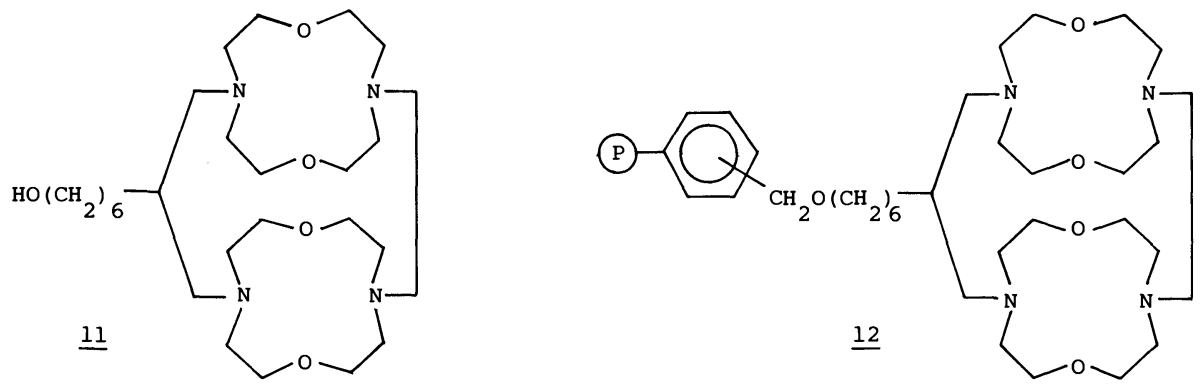

\section{REFERENCES}

1. B. Dietrich, J.M. Lehn and J.P. Sauvage, Tetraahedron Lett. 2885 (1969).

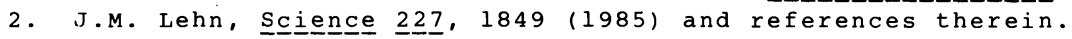

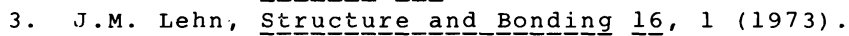

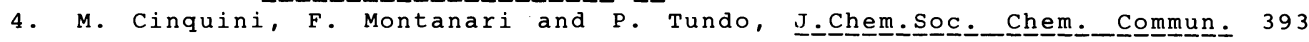
(1975).

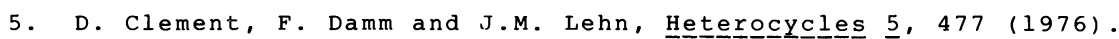

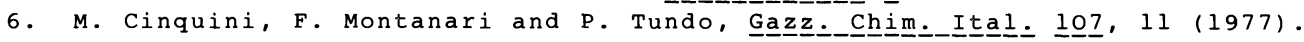

7. D. Landini, F. Montanari and F. Rolla, synthesesis 223 (1978).

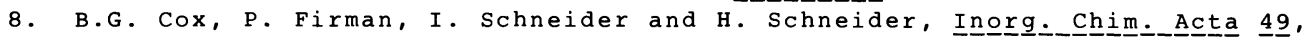
$153(1981)$.

9. B.G. Cox, Ng Van Truong, J. Garcia-Rosas and H. Schneider, J.․hys. Chem. $\underline{8}$, $996(1984)$.

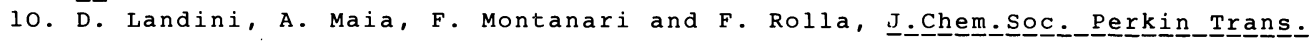
2821 (1981).

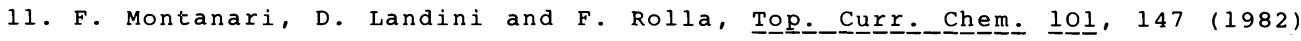
and references therein.

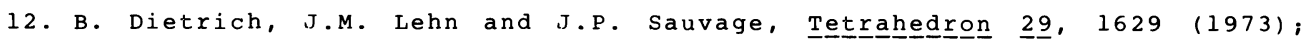
íbíd, 1647 .

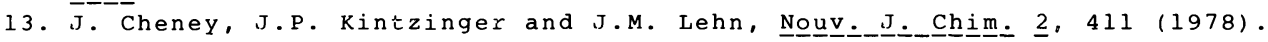

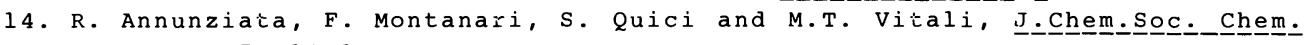
Co으uㅡㅁㅡ. 777 (1981).

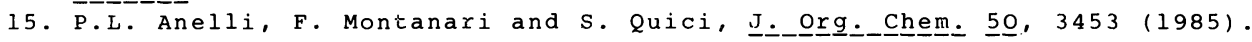

16. F. Montanari, S. Quici and P.L. Anelli, It. Patent Application 22136 A/85 (1985).

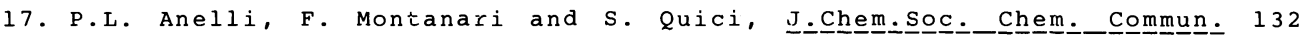
(1985).

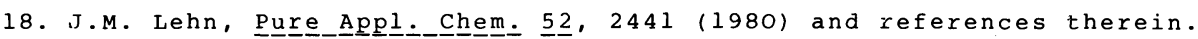

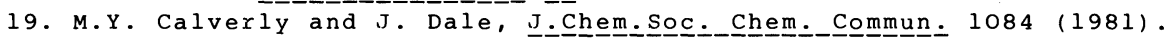

20. S. Quici, A. Sironi et al., unpublished results.

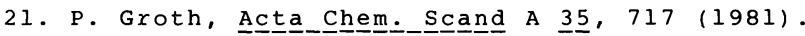

22. P.L. Anelli, T. Beringhelli, F. Montanari, H. Molinari and S. Quici,

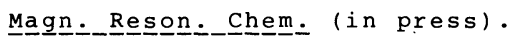

23. S. Quici, H. Molinari et al., to be published.

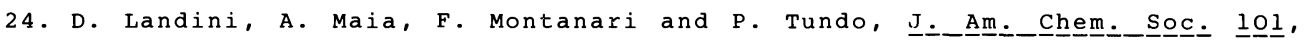
2526 (1979).

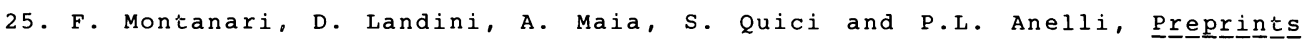

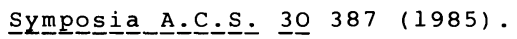

26. D. Landini and A. Maia, J

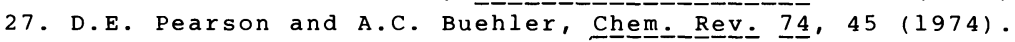

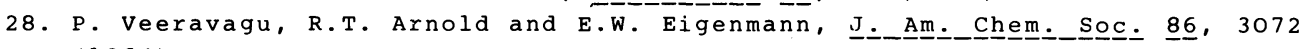
(1964).

29. S. Quici et al., unpublished results.

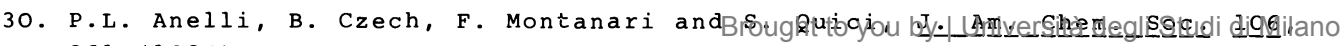
$861(1984)$. 